\title{
Classifying Exchange Rate Regimes: 15 Years Later
}

Eduardo Levy-Yeyati and Federico Sturzenegger

CID Faculty Working Paper No. 319

June 2016

Copyright 2016 Levy-Yeyati, Eduardo; Sturzenegger, Federico; and the President and Fellows of Harvard College

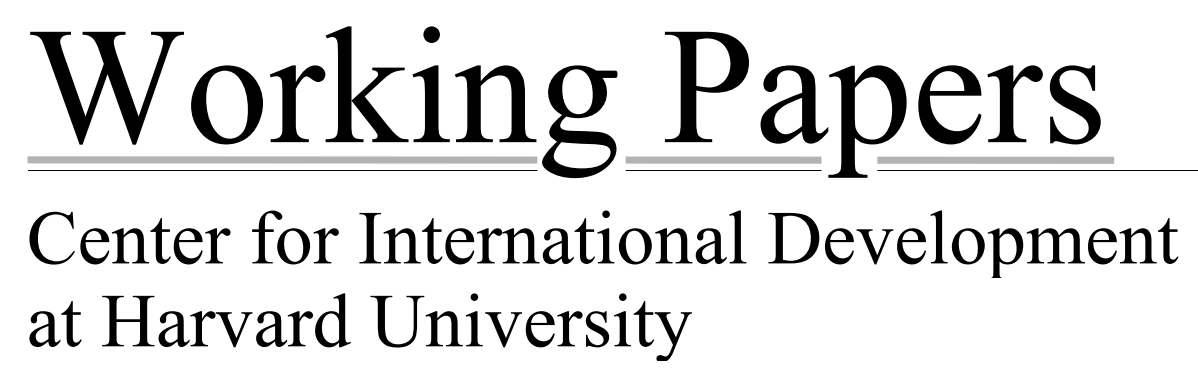




\title{
Classifying exchange rate regimes: 15 years later
}

\author{
Eduardo Levy-Yeyati, Federico Sturzenegger ${ }^{1}$
}

\begin{abstract}
Levy Yeyati and Sturzenegger $(2001,2003,2005)$ proposed an exchange rate regime classification based on cluster analysis to group countries according to the relative volatility of exchange rates and reserves, thereby shifting the focus from a de jure to de facto approach in the empirical analysis of exchange rate policy. This note extends the classification through 2014 and broadens the country sample, increasing the number of classified country-year observations from 3335 to 5616. Based on this extension, the note documents the main stylized facts in the 2000s, including the behavior of exchange rate policy around the global financial crisis, and the prevalence of floating regimes.
\end{abstract}

\section{JEL classification: F30; F33}

Keywords: Exchange rate regimes; fear of floating; fear of appreciation

\section{Introduction}

The analysis of the implications of alternative exchange rate regimes is arguably one of the key questions in international economics, as well as one with important measurement obstacles. Up until the late 90s most of the empirical discussion on exchange rate regimes used the official (de jure) regime classification that the IMF compiled based on the exchange rate arrangements periodically reported by the country's monetary authorities, despite well-documented mismatches between reports and reality. For instance, it was recognized that many alleged floaters intervened in foreign exchange markets so pervasively that, in terms of the exchange rate flexibility-monetary autonomy mix, in practice they behaved closer to a conventional peg. Conversely, many pegged regimes with autonomous (and often inconsistent) monetary policies realigned the parity so often that they behave, for most practical purposes, as floats.

\footnotetext{
${ }^{1}$ Eduardo Levy Yeyati is Visiting Professor of Public Policy at Harvard Kennedy School of Government and professor at Universidad Torcuato Di Tella's Business School. Federico Sturzenegger is Governor of the Central Bank of Argentina, and professor at Universidad Torcuato Di Tella's Business School. The authors thank Ernesto Quinto Van Peborgh for outstanding research assistance.
} 
These discrepancies - more precisely, the inadequate mapping of a classification uniquely based on official reports on actual policies- tended to mislead and ultimately frustrate empirical work in the field. Attempts to identify the benign effect of pegs on chronic inflation or the link between exchange rate flexibility and the depth of the business cycle were hampered by miss-classification problems. ${ }^{2}$

A new approach to address this problem was preliminary outlined by Ghosh et al. (1997) in light of the counterintuitive lack of empirical association between inflation and pegs. The authors mitigated the measurement bias by filtering out pegs that were realigned (devalued) more than once a year. ${ }^{3}$ This useful shortcut, has a few drawbacks, particularly in the description of non-pegs that displayed changes in both exchange rate and the reserve stock: was the observed exchange rate variability large relative to market pressure (as in a float) or small despite market pressure (as in a massive but ultimately unsuccessful attempt to defend the fixed parity, which in principle should be closer to a peg)?

Levy Yeyati-Sturzenegger (2001) introduced a first try to address these concerns, building a de facto classification by comparing the relative exchange rate and reserve volatilities. ${ }^{4}$ Underlying this choice was a textbook definition of exchange rate regimes, whereby fixed regimes are associated with changes in international reserves aimed at limiting the volatility of the nominal exchange rate, and flexible regimes are characterized by stable reserves and volatile exchange rates. The combined analysis of these three classification variables should be sufficient, they argued, to assign regimes to a broad fix-float grouping, independently of the country's official report. ${ }^{5}$ This approach was followed by other similar efforts, most notably by Reinhart and Rogoff (2002) and Shambaugh (2004), that combined de jure and de facto aspects to characterize exchange rate policies more precisely. ${ }^{6}$ More recently, the IMF replaced its traditional de jure

\footnotetext{
${ }^{2}$ An interesting contrast was provided by the (at the time) relatively new literature on the impact of a common currency on trade and economic performance (Frankel and Rose, 2000; Rose, 2000). Since the presence of a common currency is easily verifiable, the empirical analysis of currency unions was much more precise than that of other exchange rate regimes.

${ }^{3}$ Frieden et al. (2001) also modified the standard IMF classification to account for frequent adjusters and for different types of crawls for a group of selected countries.

${ }^{4}$ More precisely, it identified exchange rate regimes based on the relative behavior of three classification variables: changes in the nominal exchange rate, the volatility of those changes, and the volatility of international reserve changes.

${ }^{5}$ The paper clustered observations of three classification variables at a country-year level, and assign them intuitively: the cluster with relatively high volatility of reserves and low volatility in the nominal exchange rate was associated with pegs. Conversely, the cluster with low volatility in international reserves and volatility in the nominal exchange rate was identified with floats. Finally, countries with intermediate levels of volatility were labeled "intermediates" -a group that included, among others, economies with managed floats, binding exchange rate bands and frequently realigned pegs.

${ }^{6}$ In addition to providing a detailed story of exchange rate regimes at the country level, Reinhart and Rogoff "verified" the de jure regime: for example, a fixed exchange rate regime was verified if the exchange rate was fixed; if not, it was reclassified into another category. In addition, they considered
} 
classification by a subjective de facto one prepared by its own country desks (Habermeier et al., 2009). These new de facto classifications have delivered a large and growing body of literature examining the determinants and consequences of exchange rate policy on many macroeconomic variables. ${ }^{7}$

The new millennium has witnessed important developments regarding exchange rate regimes: currency appreciation in most developing countries coupled with the gradual decline in their net foreign currency liabilities, transitorily interrupted by the global financial crisis; heavy leaning-against-the-wind exchange rate intervention, including by formerly non-interventionist countries like Israel or Switzerland; a gradual flexing of the Chinese peg. Are we in the presence of a new paradigm that combines an inflation targeting or inflation-centered policy with a more active management of the exchange rate? Can we say that the new millennium marked the comeback of exchange rate policies? More generally, how well known individual stories alter the regime map when seen from a full global perspective? To address these questions and to identify the new patterns, if any, of exchange rate policies in the 2000s, this note updates Levy Yeyati-Sturzenegger's (2001) and discusses the key stylized results from the extended de facto classification.

The plan is as follows. Section 2 describes the additional data included in this new exercise, briefly revisits the cluster methodology, and describes a first characterization of regimes in the 2000s. Section 3 presents the classification (described in more detail in Appendix C) and its main stylized facts. Section 4 concludes.

\section{Methodology}

\subsection{Classification variables}

According to the textbook description, flexible exchange rates are characterized by little intervention in the exchange rate markets together with unlimited volatility of the nominal exchange rate. Conversely, a fixed exchange rate regime occurs when the exchange rate does not move while reserves are allowed to fluctuate. Under a crawling peg, changes in the nominal exchange rates occur with stable increments (i.e. low volatility in the rate of change of the exchange rate) while active intervention keeps the exchange rate along that path. Finally, a dirty float should be associated to the case in which volatility is relatively high across all variables, with intervention only partially smoothing exchange rate fluctuations.

With this in mind, regimes could be broadly characterized by the relative behavior of three classification variables: the exchange rate volatility $\left(\sigma_{e}\right)$,

the existence of dual exchange rates that used to be frequent in the developing world in the past. Shambaugh, in turn, used a purely statistical approach similar to the LYS classification, but base entirely on the volatility of the exchange rate.

${ }^{7}$ See Levy Yeyati and Sturzenegger (2010) for a survey of the literature. 
measured as the average of the absolute monthly percentage changes in the nominal exchange rate during a calendar year, ${ }^{8}$ the volatility of exchange rate changes $\left(\sigma_{\Delta e}\right)$, computed as the standard deviation of monthly percentage changes in the exchange rate, and the volatility of reserves $\left(\sigma_{r}\right)$.

To compute the first two variables we need to choose an appropriate reference currency. In some cases this poses no problem (for example, we use the U.S. dollar for the Mexican peso and the Deutsche Mark for the Italian lira) but the reference currency is not always obvious (for example, for the UK pound or the Swiss franc, the US dollar and the Deutsche Mark both appear to be, a priori, equally good candidates). To sort out these ambiguous cases we use the following criterion: if the country reports a peg we use the legal peg currency; otherwise, we use the currency against which it exhibits the lowest exchange rate volatility. Countries that peg to a basket are eliminated from the sample unless the central peg parity or the basket weights are disclosed..$^{10} \mathrm{~A}$ list of the reference currencies used in each case is reported in Appendix B.

Our third classification variable, the volatility of reserves $\left(\sigma_{r}\right)$, requires particular care. Reserves are notoriously difficult to measure, as there is usually a difference between changes in reserves and the actual volume of intervention. ${ }^{11}$ To approximate as closely as possible the change in reserves that reflects intervention in the foreign exchange market, we subtract government deposits at the central bank from the central bank's net foreign assets. ${ }^{12}$ More specifically, we define net reserves in U.S. dollars as:

\footnotetext{
${ }^{8}$ Choosing a calendar year as unit of account implies that in years where the exchange rate regime changes, the yearly number will reflect a combination of both regimes. Argentina, for example, implemented a fixed exchange rate in April of 1991. Our yearly data takes into account the strong movements in the nominal exchange rate during the first three months of the year and, as a result, the country is classified as a dirty float. Similarly Ecuador, which dollarized in late January 2000 is classified as crawling peg for that year. This improves upon IMF (1997) and Ghosh et al. (1997), which use the legal regime as of the end of each year.

${ }^{9}$ For this exercise we considered the US dollar, the French franc, the German mark, the British pound, the SDR, the ECU and the Japanese yen. For some small countries the currency of a large neighbor was also considered.

${ }^{10}$ If the basket is not known it is impossible to assess whether the country is intervening or not to defend a predetermined parity.

${ }^{11}$ See the careful discussion in Eichengreen et al. (1996) in the context of the European Union. In addition, the timing of intervention is not always accurate, as central banks economies with sophisticated foreign exchange markets tend to intervene using derivatives such as currency futures or swaps, delaying and often smoothing out changes in the stock of reserves.

12 Oil producing countries and countries with important privatization programs are examples of cases where the latter correction matters. Calvo and Reinhart (2000) indicate other reasons (hidden foreign exchange transactions, use of credit lines, derivative transactions, or issuance of debt in foreign currency) that make it difficult to compute the real movement in reserves. To these one could add coordinated intervention by other central banks (though this should be limited to G-3 economies) and the measurement error introduced by the fact that all accounts are transformed to dollar units: If the Central Bank holds a portfolio of assets with several currencies, changes in the parities between the reserve currencies can be mistaken for foreign exchange interventions. We believe this measurement error problem to be minor as most of the reserves are in dollar denominated assets.
} 


$$
R_{t}=\frac{\text { ForeignAssets }_{t}-\text { ForeignLiabilities }_{t}-\text { CentralGov.De posits }_{t}}{e_{t}},
$$

where $e$ indicates the price of a dollar in terms of local currency. ${ }^{13}$ Our measure of the monthly intervention in the foreign exchange market, $r_{t}$, is in turn defined as

$$
r_{t}=\frac{R_{t}-R_{t-1}}{\frac{\text { Monetary }_{\text {Base }} t-1}{e_{t-1}}}=\frac{\Delta R}{\frac{\text { Monetary }_{\text {Base }_{t-1}}}{e_{t-1}}} .
$$

Finally, our volatility measure is computed as the average of the absolute monthly change in net international reserves, $r_{t}$, relative to the monetary base at the beginning of the month. ${ }^{14}$

Note that the use of both policy (intervention) and outcomes (exchange rate changes) as classification variables is crucial to gauge the intensity of the policy response. For example, a peg would respond to small exchange rate shocks with small interventions, and to large shocks with large interventions. Thus, a regime under a stable environment (small shocks) could be misleadingly identified as a float based on interventions and as a peg based on exchange rate volatility. Similarly, an exchange rate realignment as a result of market pressure coupled with heavy intervention may be viewed as a float based on exchange rates and as a peg based on reserves. In both cases, it is the relative variation of policy and outcomes that better characterizes the true reaction function underlying the regime. ${ }^{15}$

These three classification variables yield three-dimension country-year observations for each of the IMF-reporting countries included in the sample and each year of our time sample (1974-2013). ${ }^{16}$ Of the potential 7304 observations,

${ }^{13}$ All central bank items are denominated in local currency and the time period for all variables corresponds to the end of period for a specific month.

${ }^{14}$ In practice we use line $11 \ldots$ (or FASAF when available) from the IFS for foreign assets, line 16____ (or FASLF when available) for foreign liabilities and 16d__ (or FASLG when available) for central government deposits. Line 14__ (or FASMB when available or 14a _ if previews options were not available) lagged one month is used as a measure of the monetary base. Contrary to Calvo and Reinhart (2000) we use the changes relative to the monetary base rather than the percentage change in reserves. We believe this is a better measure, as a given percentage change in reserves in countries with low monetization implies a larger relative intervention in forex markets.

${ }^{15}$ More important, we believe that the scope for interest rate policy to alter exchange market conditions without a concomitant movement in reserves is quite limited, both in duration and strength, as indicated by the lack of success of interest rate defenses against speculative attacks during our sample period. However, many of the countries in our sample include cases in which there may have been effective capital controls and/or segmented capital markets where interest rate policy may have been a more feasible stabilization instrument. Yet, as is well known, the literature has identified two channels through which this (sterilized) intervention can affect interest rates: a signaling-expectation effect and a portfolio risk premium effect.

${ }^{16}$ This still excludes some fixed exchange rate countries that are not IMF country members such as Andorra, Liechenstein, Monaco, Nauru, Tuvalu and Vatican City, all of them fixed throughout the 
679 are left out due to undisclosed basket pegs and another 1437 lack data for at least one of the classifying variables, leaving a final sample of 5198 observations.

\subsection{Classification procedure}

We use cluster analysis to identify the regime groups based on the previously described classification variables. ${ }^{17}$ Cluster analysis is a multivariate procedure used to identify homogeneous groups of observations according to similarities (distances) along certain quantitative dimensions, a natural approach if the objective is to classify observations by comparison with other data points.

There are two approaches within the cluster analysis technique. Hierarchical Cluster Analysis (HC), typically used for small samples, allows for some additional discretion in determining the way distances are measured, in the order the sample is introduced and in how the classification itself is constructed. HC starts from a matrix of distances between pairs of elements (the two closest are grouped in one cluster) and may differ in how distances between clusters are estimated at successive steps. Alternatively, centroid sorting (KMC; Anderberg, 1973) assign individual cases to the cluster with the smallest distance between the case and the center of the cluster (centroid). The number of clusters, $K$, is specified ex-ante by the user, and cluster centers are iteratively estimated from the data. While HC seeks to unveil a nested pattern or grouping of objects, KMC seeks to find the best K-group classification of the observations with the least intervention from the researcher (only our definition of $K$ is needed ex ante). Since it is crucial to our work that the classification involves a minimal manipulation of the classification criteria, we choose KMC as our cluster methodology. ${ }^{18}$

Once the three classification measures are computed for our universe of countries, the KMC algorithm assigns the data to five different groups that represent a distinct exchange rate regime (Table 1). Because KMC uses the relative distance between points, it is important that all three measures should be comparable. To that end, we first eliminate the two percent-upper tail of observations for each of the three classification variables, which excludes 226 outliers out of 5188 data points. ${ }^{19}$ We then z-normalize the remaining 4962 observations and use the K-means algorithm to classify the data into the five clusters described above.

\footnotetext{
post-Bretton Woods period (Tuvalu since 1979). See Obstfeld and Rogoff (1995). We also exclude many semi-independent countries, dependencies or territories. On these see Rose (2000). All other countries are included.

${ }^{17}$ Refer to Levy Yeyati and Sturzenegger (2005) for a more extensive description.

${ }^{18}$ The only restriction is that because the procedure is measure dependent all variables need to be $\mathrm{z}$ normalized.

${ }^{19}$ Because these outliers do not present classification problems, we re-classify these observations expost, by assigning them to the cluster with the nearest centroid. The $2 \%$ threshold was chosen arbitrarily. Alternative values for this threshold delivered virtually identical classifications.
} 
In turn, since observations that display little variability along the three variables cannot be assigned to any particular group at this stage, they are labeled "inconclusives" and left unclassified. ${ }^{20}$ This initial, first-round classification assigns 2050 data points and allocates a large number of observations (2912 out of 4962) to the "inconclusive" category. While variations in the classification variables within this group may be small relative to the data points clustered in the first round, the data still displays enough volatility to identify exchange rate regimes within the inconclusive group. This is done in a second round using the same methodology as in the first one. The second-round procedure assigns 1606 out of the 2912 inconclusive observations, leaving 1306 observations unclassified.

The distinction between first and second round, which mirrors observations with high and low variability, provides an additional refinement to the classification. By introducing this dimension, the methodology allows to discriminate, albeit in a crude manner, the intensity of the shocks to which the regime is subject, something that qualitative indexes previously used did not. The classification algorithm is summarized in Figure 1.

\subsection{An extended classification}

The methodology assigns an exchange rate regime to most data points in the sample, and leave 1306 second-round inconclusives unclassified. Additionally, the sample includes 1437 country-years for which some of the classification variables were not available (Figure 2).

Table 2 shows, for each cluster, the central values as well as the upper and lower bounds of the classification variables. Comparing the centroid values, fixed regimes are characterized by relatively low nominal exchange rate volatility (with an average absolute change of $0.60 \%$ per month as opposed to $1.59 \%$ in the case of floats), and high volatility in reserves (19.15\% against $5.66 \%$ for floats). The two intermediate groups, on the other hand, exhibit not only substantial intervention in the exchange rate market but also the highest exchange rate volatility. This evidence suggests the following important point: pure floats appear to tolerate relatively minor fluctuations in the exchange rate. Conversely, as a rule, countries with substantial movements in the nominal exchange rate usually intervene actively. The table also shows that second round groups present less overlap between fixers and floaters. While the former exhibit an absolute monthly volatility of the nominal exchange rate that ranges from zero to $0.40 \%$, the minimum exchange rate volatility for the latter is $0.26 \%$. Regarding international reserves, floaters display an average absolute change ranging between $0.35 \%$ and $7.39 \%$ of the monetary base, in contrast with a minimum reserve variability of $6.16 \%$ for fixers.

\footnotetext{
${ }^{20}$ If neither the nominal exchange rate nor reserves move, the exchange rate regime that the country is actually implementing is not obvious from direct comparison with the rest of the sample.
} 
Many of these unclassified observations can still be identified in an uncontroversial fashion (e.g., Panama's or Ecuador's unilateral dollarization or Hong-Kong's currency board agreement). To include as many observations as possible, we extend the classification using additional information on specific countries left unclassified by the previous methodology. Specifically, a fixed exchange rate regime is assigned to inconclusives that met one of these two criteria: (i) exhibits zero volatility in the nominal exchange rate, or (ii) was identified as a peg by the IMF and had an average volatility in the nominal exchange rate smaller than $0.1 \%$ (placing them safely off-limits from the second round-float and dirty-float clusters). 1131 out of the 1306 cases are classified as pegged regimes in this way.

Using the same approach to identify pegs within the 1437 country-years excluded due to lack of data, a total of 603 observations were added to the final grouping. ${ }^{21}$ Importantly, this group includes 200 observations corresponding to euro members, 187 of which were classified as floats and 13 as crawling peg. Extending the classification in this way brings up the question about how to consider countries currently within the Euro zone. Countries without a national currency pose a problem: should Greece, for example, be regarded as California and classified as a float given how the euro behaves relative to other currencies, or should the common currency be the relevant aspect to classify the Greek regime as a peg? This is an open question, the answer to which should depend on the issue at stake, and each researcher can easily choose the approach as he sees fit. In our tables, we choose the first option and classify these countries as we do with the euro as a whole: float since 1998 (with the sole exception of an intermediate regime in 2008). A useful analogy is the case of WAEMU, where we also classify the regime of each member country according to the behavior of the common currency -although because the common currency in this case is fixed for the most part, there is less disagreement between the two approaches).

Table 3 shows the final three-way distribution of observations into floats, intermediate (including crawling pegs and dirty floats) and fixed regimes.

\section{The prevalence of floating regimes}

A first glance at the classification suggests that the steady decline in the number of fixes since the demise of Bretton Woods accelerated during the past decade. Figure 3 shows the relative importance of fixed, intermediate, and floating regimes, and the trends towards exchange rate flexibility. While the decline initially came from a lower number of fixed regimes (in most cases, a Bretton Woods legacy), in recent years the reduction came at the expense of intermediate

21 Unclassified observations comprise pegs to undisclosed baskets (679) and inconclusive observations (175) and countries with missing data (834). 
regimes: more and more intermediates allow their exchange rates to float more freely.

Figures 4 and 5 show that, with a predictable impasse during the global financial crisis, the growing popularity of floats is explained largely by exchange rate policies in high- and middle-income economies, while for low-income economies pegs remained the preferred choice with only a limited migration to floats prior to 2000. This is consistent with another significant finding: the number of countries which run a fixed exchange rate regime without explicitly stating that they do, ("fear of pegging", according to Levy Yeyati and Sturzenegger, 2001) has increased remarkably over the last decade. The same could be said of regimes that are officially but not de facto floating (Calvo and Reinhart's (2002) "fear of floating"). Overall, the prevalence of floats among financially integrated economies goes in line with a declining mismatch between words and deeds.

The shift to floats may also reflect the fact that increasingly global capital markets have weakened even the strongest pegs in financially integrated economies, forcing a steady movement to more flexible arrangements that, crucially, involve discretionary intervention rather than a predetermined parity. But appears at odds with the stability in the use of fixed regimes since the early 90s, a point that challenges the view that increasing capital market mobility was the driver behind the gradually abandonment of fixed arrangements. More generally, the transition between intermediates and floats, which reversed partially in the most recent period, may simply indicate that exchange rate policy is endogenous to the local and the global contexts, and swings between exchange rate stability and variability according to markets pressure and whether deviations and high frequency volatility are seen as an unnecessary source of nominal uncertainty.

\section{Final remarks}

The literature has, for the last 15 years, developed de facto alternatives to the de jure exchange regime classifications. In this note we contribute to that end by extending Levy Yeyati and Sturzenegger's (2001) classification to the present, and summarizing a few basic findings that emerge from a casual inspection of the results. 


\section{References}

Anderberg, M.R., 1973. Cluster Analysis for Applications. Academic Press, New York.

Calvo, G., Reinhart, C., 2000. Fear of floating. Quarterly Journal of Economics 117 (2), 379-408.

Eichengreen, B., Rose, A., Wyplosz, C., 1996. Speculative attacks on pegged exchange rates: An empirical exploration with special reference to the European Monetary System. NBER Working Paper No. 4898, NBER, Cambridge, MA.

Frankel, J., Rose, A., 2000. Estimating the effect of currency unions on trade and output. NBER Working Paper No. 7857, NBER, Cambridge, MA.

Frieden, J., Ghezzi, P., Stein, E., 2001. Politics and exchange rate: A cross-country approach. In: Frieden, J., Stein, E. (Eds.), The Currency Game: Exchange Rate Politics in Latin America. IADB, Washington, DC.

Ghosh, A., Gulde, A., Ostry, J., Wolf, H., 1997. Does the nominal exchange rate regime matter? NBER Working Paper No. 5874, NBER, Cambridge, MA.

Hartigan, J.A., 1975. Clustering Algorithms. John Wiley \& Sons, Inc., New York.

Habermeier, K., Kokenyne. A., Veyrune, R., and Anderson, H., 2009. Revised System for the Classification of Exchange Rate Arrangements.

Levy Yeyati, E., Sturzenegger, F., 2001. Exchange rate regimes and economic performance. IMF Staff Papers 47, 62-98.

Levy Yeyati, E., Sturzenegger, F., 2003. To float or to fix: Evidence on the impact of exchange rate regimes on growth. American Economic Review 93 (4), 1173-1193.

Levy Yeyati, Eduardo \& Sturzenegger, F., 2010. "Monetary and Exchange Rate Policies," in Rodrik, D. Handbook of Development Economics, Elsevier.

Obstfeld, M., Rogoff, K., 1995. The mirage of fixed exchange rates. NBER Working Paper No. 5191, NBER, Cambridge, MA.

Rose, A., 2000. One money, one market? The effect of a common currency on international trade. Economic Policy 30, 9-45. 
Table 1

Classification criteria

\begin{tabular}{llll} 
& $\sigma_{e}$ & $\sigma_{\Delta e}$ & $\sigma_{r}$ \\
\hline Inconclusive & Low & Low & Low \\
Flexible & High & High & Low \\
Dirty float & High & High & High \\
Crawling peg & High & Low & High \\
Fixed & Low & Low & High \\
\hline
\end{tabular}


Table 2

Cluster boundaries

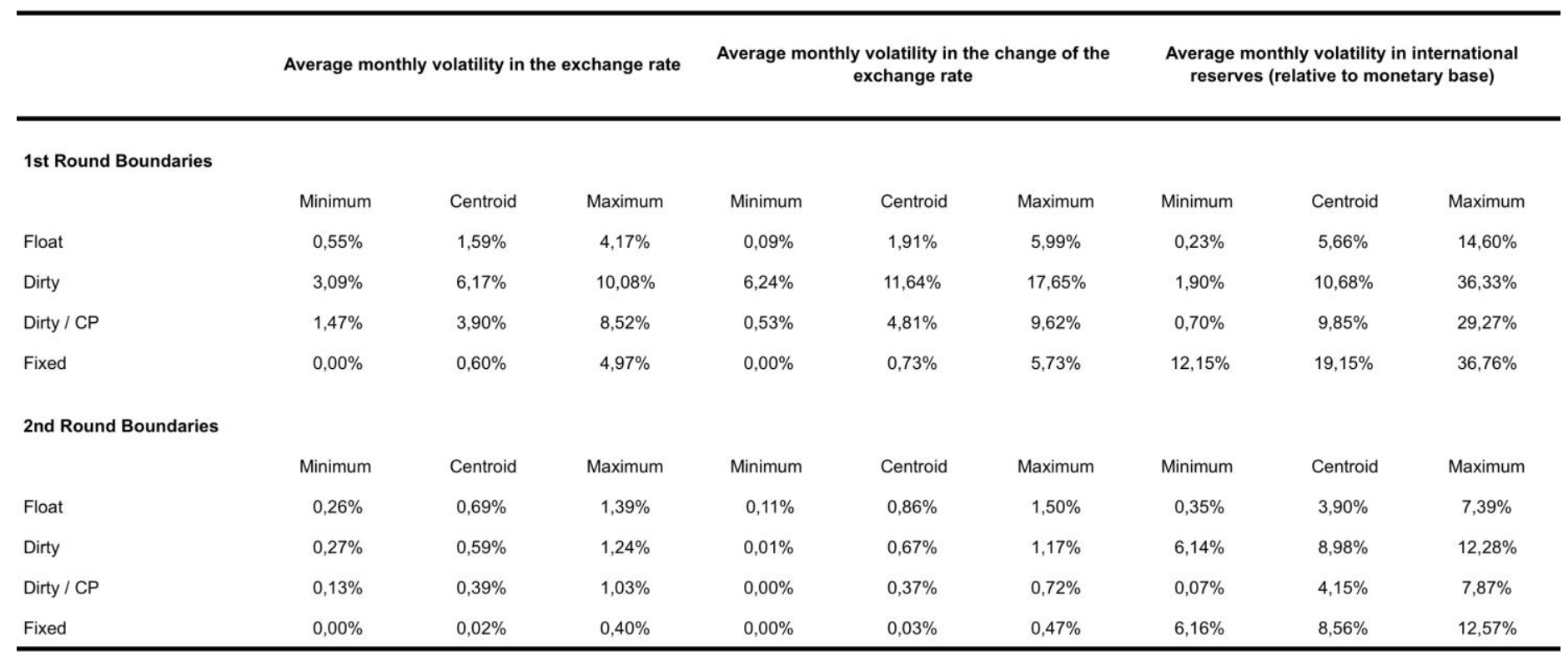


Table 3

LYS classification

\begin{tabular}{|c|c|c|c|c|c|c|}
\hline Regime & 1st Round & 2nd Round & Outliers & Inconclusives & Ad-hoc & LYS \\
\hline Float & 1095 & 302 & & & & 1397 \\
\hline Intermediate & 399 & 536 & 127 & & & 1062 \\
\hline Fix & 556 & 768 & 99 & 1131 & 603 & 3157 \\
\hline Total & 2050 & 1606 & 226 & 1131 & 603 & 5616 \\
\hline
\end{tabular}


Table 4

Exchange rate regimes LYS vs IMF classification (in \%)

\begin{tabular}{|c|c|c|c|c|c|c|c|c|c|c|c|c|c|c|}
\hline Year & $\begin{array}{l}\text { Float / } \\
\text { float }\end{array}$ & $\begin{array}{l}\text { Float / } \\
\text { interm. }\end{array}$ & $\begin{array}{c}\text { Float / } \\
\text { fix }\end{array}$ & $\begin{array}{c}\text { Interm. I } \\
\text { float }\end{array}$ & $\begin{array}{c}\text { Interm. / } \\
\text { interm }\end{array}$ & $\begin{array}{c}\text { Interm. I } \\
\text { fix }\end{array}$ & $\begin{array}{l}\text { Fix I } \\
\text { float }\end{array}$ & $\begin{array}{c}\text { Fix / } \\
\text { interm. }\end{array}$ & Fix / fix & Match & Mismatch & $\begin{array}{c}\text { Fear of } \\
\text { Peg }\end{array}$ & $\begin{array}{c}\text { Fear of } \\
\text { Float }\end{array}$ & $\begin{array}{c}\text { Total Number } \\
\text { of Cases }\end{array}$ \\
\hline 1974 & 6 & 7 & 9 & 0 & 3 & 8 & 0 & 3 & 68 & 77 & 27 & 3 & 0 & 104 \\
\hline 1975 & 5 & 7 & 8 & 0 & 7 & 11 & 0 & 3 & 63 & 75 & 29 & 3 & 0 & 104 \\
\hline 1976 & 4 & 8 & 6 & 0 & 7 & 11 & 0 & 3 & 61 & 72 & 28 & 3 & 0 & 100 \\
\hline 1977 & 12 & 8 & 2 & 1 & 6 & 6 & 1 & 2 & 65 & 83 & 20 & 3 & 2 & 103 \\
\hline 1978 & 12 & 4 & 8 & 3 & 10 & 5 & 1 & 4 & 60 & 82 & 25 & 5 & 4 & 107 \\
\hline 1979 & 4 & 14 & 2 & 2 & 10 & 9 & 1 & 9 & 59 & 73 & 37 & 10 & 3 & 110 \\
\hline 1980 & 4 & 12 & 2 & 2 & 12 & 3 & 1 & 11 & 65 & 81 & 31 & 12 & 3 & 112 \\
\hline 1981 & 6 & 13 & 5 & 2 & 14 & 6 & 0 & 11 & 58 & 78 & 37 & 11 & 2 & 115 \\
\hline 1982 & 4 & 13 & 5 & 3 & 14 & 2 & 0 & 12 & 57 & 75 & 35 & 12 & 3 & 110 \\
\hline 1983 & 4 & 10 & 4 & 2 & 18 & 2 & 1 & 14 & 52 & 74 & 33 & 15 & 3 & 107 \\
\hline 1984 & 5 & 15 & 4 & 3 & 13 & 5 & 0 & 13 & 51 & 69 & 40 & 13 & 3 & 109 \\
\hline 1985 & 2 & 10 & 4 & 7 & 15 & 5 & 3 & 13 & 48 & 65 & 42 & 16 & 10 & 107 \\
\hline 1986 & 6 & 13 & 5 & 5 & 14 & 8 & 3 & 11 & 46 & 66 & 45 & 14 & 8 & 111 \\
\hline 1987 & 7 & 10 & 6 & 8 & 13 & 2 & 3 & 14 & 49 & 69 & 43 & 17 & 11 & 112 \\
\hline 1988 & 10 & 10 & 5 & 6 & 9 & 10 & 2 & 13 & 48 & 67 & 46 & 15 & 8 & 113 \\
\hline 1989 & 9 & 14 & 3 & 9 & 6 & 9 & 1 & 16 & 47 & 62 & 52 & 17 & 10 & 114 \\
\hline 1990 & 13 & 12 & 2 & 5 & 12 & 6 & 3 & 14 & 50 & 75 & 42 & 17 & 8 & 117 \\
\hline 1991 & 10 & 10 & 3 & 12 & 14 & 4 & 3 & 13 & 45 & 69 & 45 & 16 & 15 & 114 \\
\hline 1992 & 16 & 12 & 6 & 7 & 10 & 2 & 6 & 16 & 44 & 70 & 49 & 22 & 13 & 119 \\
\hline 1993 & 16 & 16 & 3 & 11 & 11 & 2 & 11 & 15 & 47 & 74 & 58 & 26 & 22 & 132 \\
\hline 1994 & 15 & 13 & 2 & 13 & 16 & 18 & 10 & 20 & 30 & 61 & 76 & 30 & 23 & 137 \\
\hline 1995 & 18 & 26 & 4 & 17 & 8 & 4 & 10 & 17 & 45 & 71 & 78 & 27 & 27 & 149 \\
\hline 1996 & 23 & 17 & 1 & 13 & 20 & 4 & 9 & 18 & 44 & 87 & 62 & 27 & 22 & 149 \\
\hline 1997 & 22 & 24 & 0 & 9 & 21 & 2 & 7 & 23 & 47 & 90 & 65 & 30 & 16 & 155 \\
\hline 1998 & 21 & 21 & 1 & 15 & 21 & 3 & 4 & 26 & 47 & 89 & 70 & 30 & 19 & 159 \\
\hline 1999 & 34 & 19 & 2 & 9 & 22 & 1 & 10 & 16 & 52 & 108 & 57 & 26 & 19 & 165 \\
\hline 2000 & 32 & 22 & 1 & 12 & 18 & 1 & 8 & 17 & 50 & 100 & 61 & 25 & 20 & 161 \\
\hline 2001 & 36 & 17 & 5 & 14 & 14 & 2 & 10 & 20 & 51 & 101 & 68 & 30 & 24 & 169 \\
\hline 2002 & 35 & 14 & 2 & 16 & 20 & 7 & 9 & 15 & 48 & 103 & 63 & 24 & 25 & 166 \\
\hline 2003 & 35 & 19 & 2 & 16 & 14 & 5 & 8 & 14 & 51 & 100 & 64 & 22 & 24 & 164 \\
\hline 2004 & 34 & 16 & 2 & 13 & 16 & 2 & 9 & 16 & 54 & 104 & 58 & 25 & 22 & 162 \\
\hline 2005 & 38 & 18 & 3 & 13 & 19 & 5 & 6 & 15 & 51 & 108 & 60 & 21 & 19 & 168 \\
\hline 2006 & 37 & 18 & 3 & 9 & 9 & 3 & 10 & 20 & 54 & 100 & 63 & 30 & 19 & 163 \\
\hline 2007 & 43 & 18 & 1 & 8 & 14 & 4 & 8 & 20 & 52 & 109 & 59 & 28 & 16 & 168 \\
\hline 2008 & 15 & 25 & 3 & 36 & 14 & 5 & 8 & 13 & 51 & 80 & 90 & 21 & 44 & 170 \\
\hline 2009 & 32 & 25 & 3 & 14 & 19 & 5 & 5 & 12 & 52 & 103 & 64 & 17 & 19 & 167 \\
\hline 2010 & 41 & 31 & 5 & 4 & 12 & 2 & 6 & 10 & 53 & 106 & 58 & 16 & 10 & 164 \\
\hline 2011 & 38 & 30 & 4 & 4 & 14 & 3 & 6 & 12 & 51 & 103 & 59 & 18 & 10 & 162 \\
\hline 2012 & 39 & 29 & 3 & 3 & 17 & 3 & 3 & 6 & 53 & 109 & 47 & 9 & 6 & 156 \\
\hline 2013 & 37 & 30 & 2 & 5 & 13 & 5 & 5 & 8 & 52 & 102 & 55 & 13 & 10 & 157 \\
\hline Total & $14,4 \%$ & $12,0 \%$ & $2,6 \%$ & $6,1 \%$ & $9,9 \%$ & $3,7 \%$ & $3,5 \%$ & $9,7 \%$ & $38,1 \%$ & $62,4 \%$ & $37,6 \%$ & $13,2 \%$ & $9,6 \%$ & 5431 \\
\hline
\end{tabular}




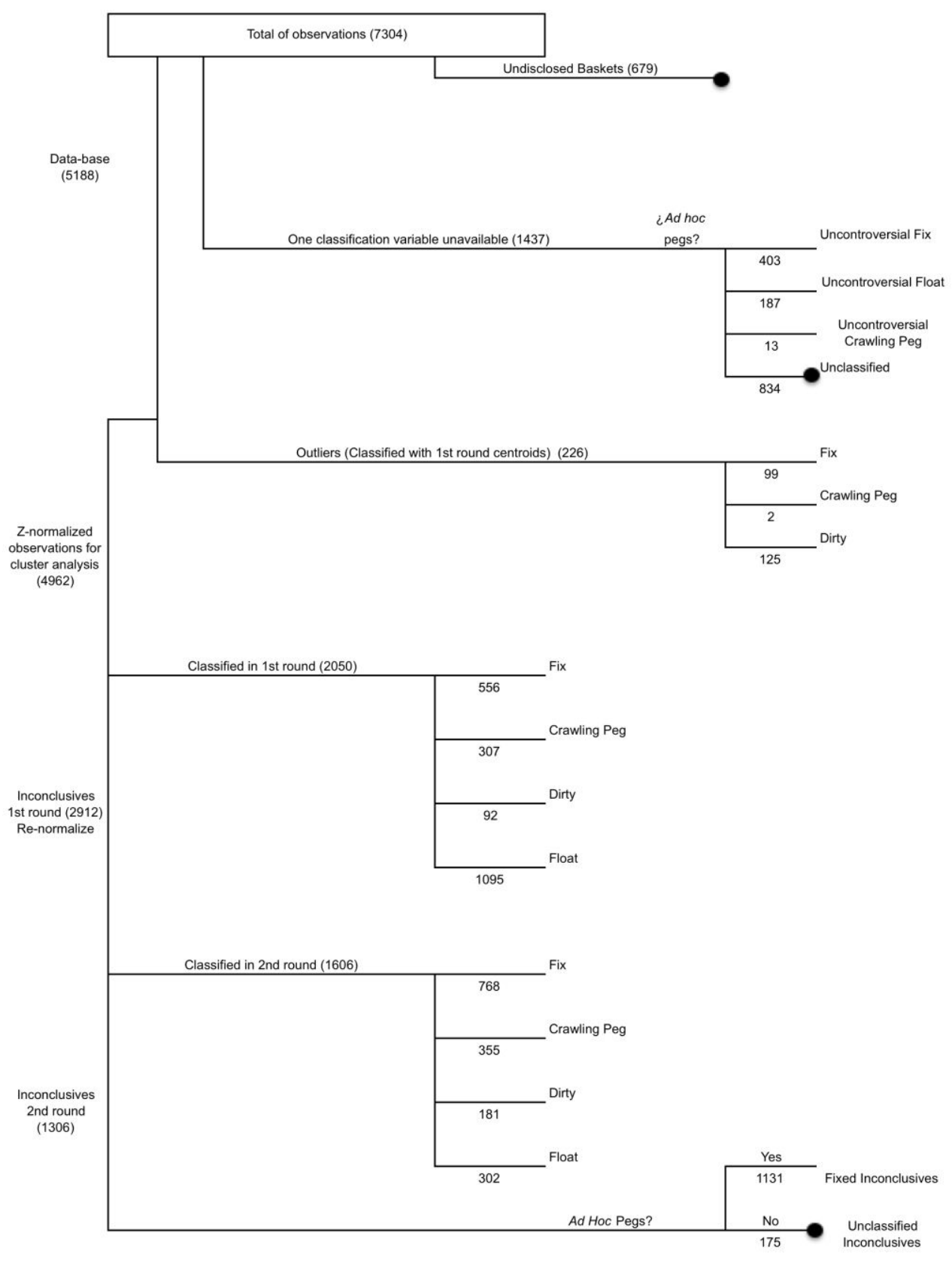

Figure 1. Exchange rate classification. 

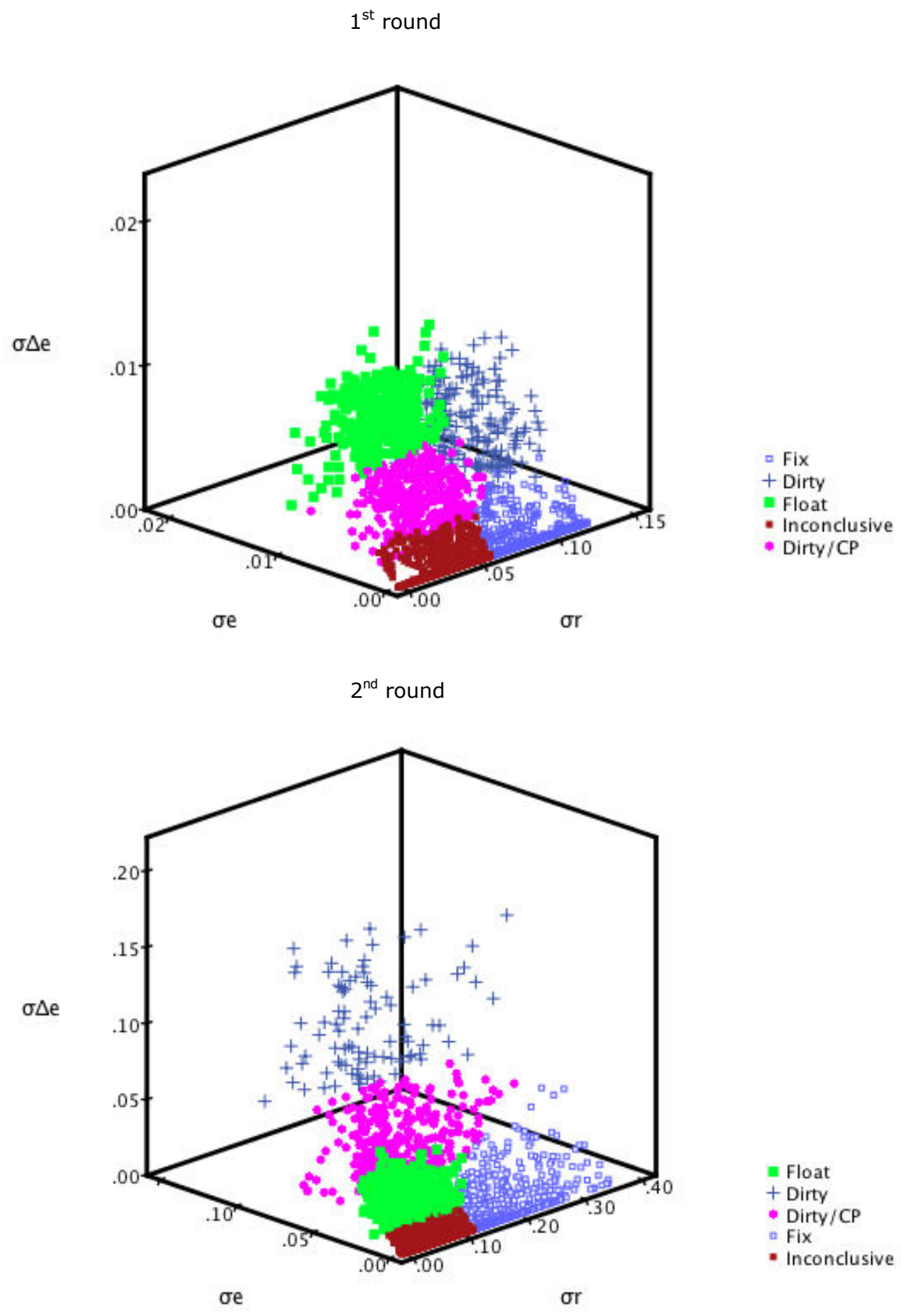

Figure 2. First-round and second-round observations. 


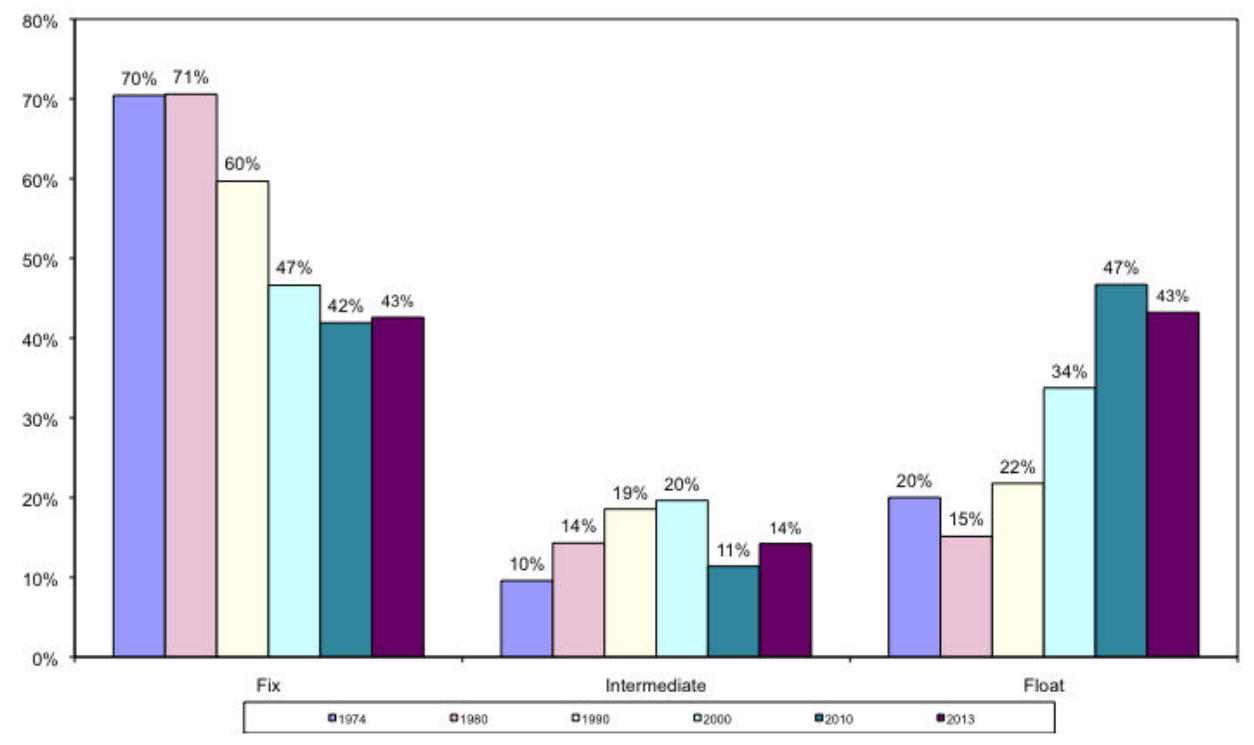

Figure 3. Distribution of exchange rate regimes LYS classification (1974-2013). 


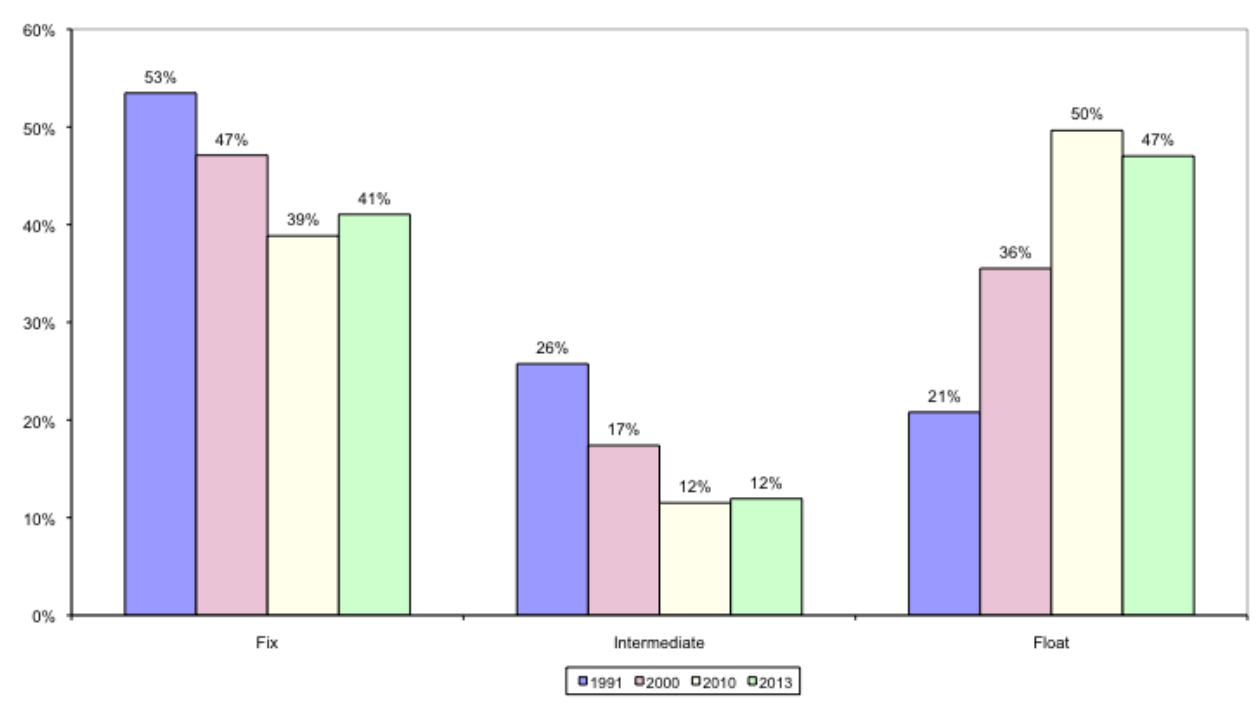

Figure 4. Developed and emerging countries (LYS classification).

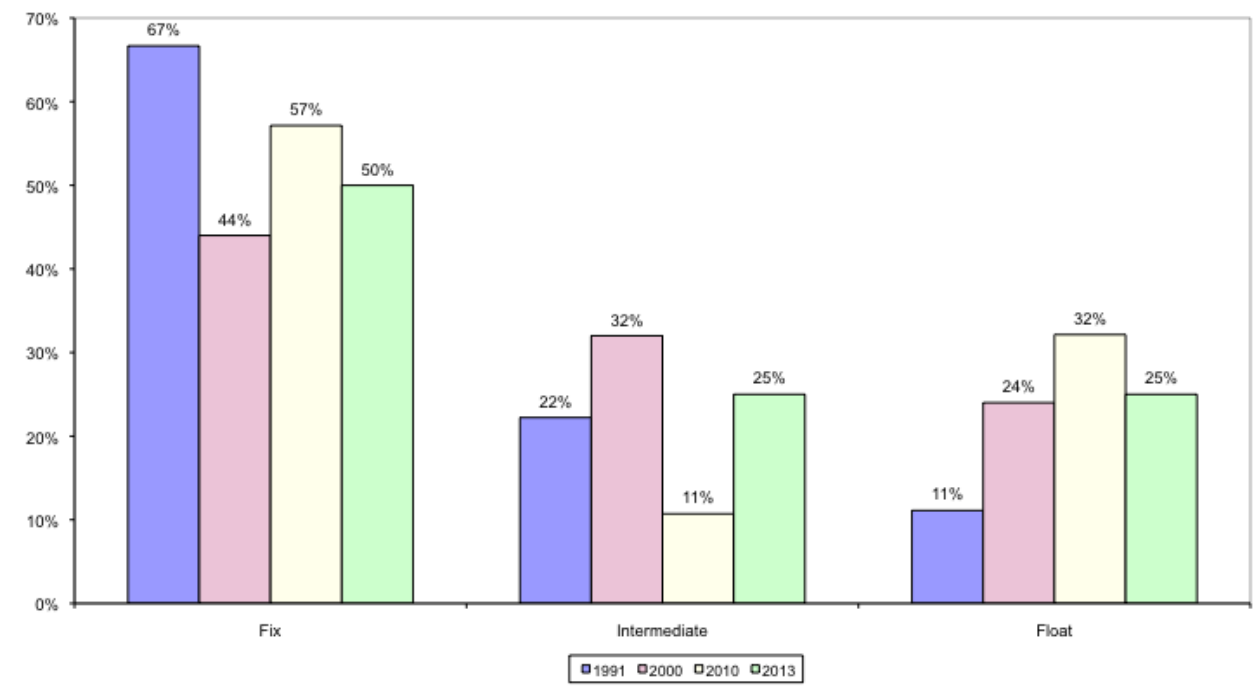

Figure 5. Other countries (LYS classification). 


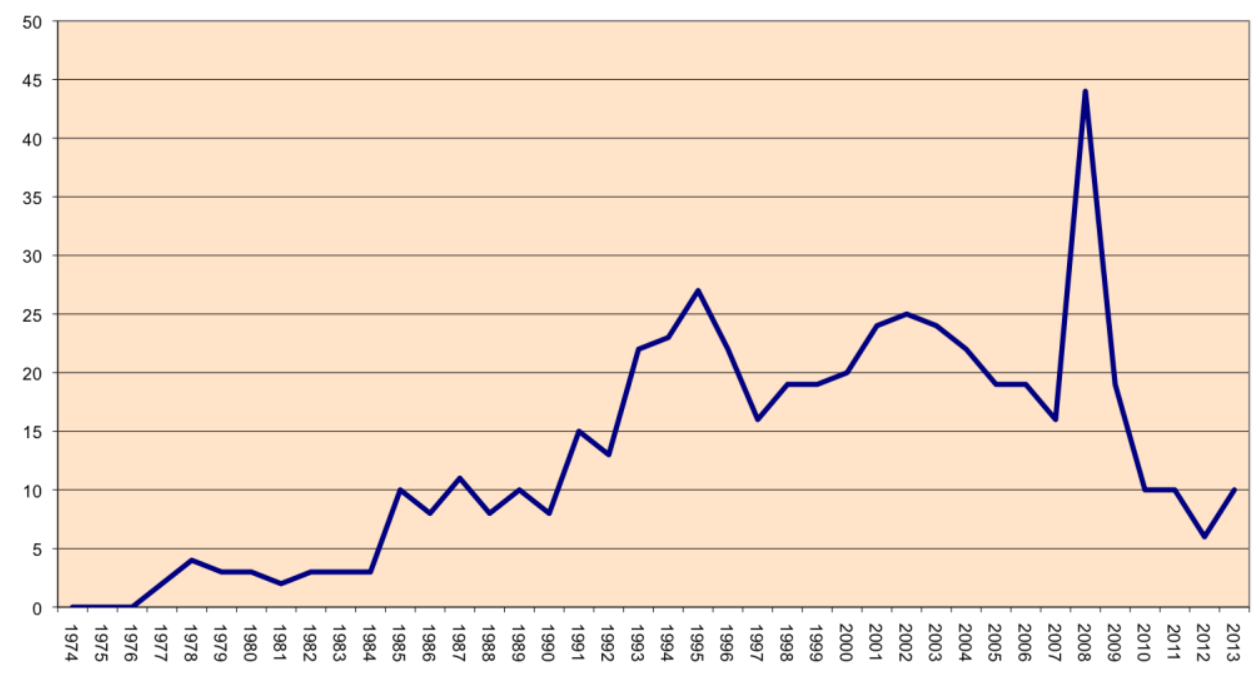

Figure 6. Fear of floating (number of de jure flotas that de facto are not floats).

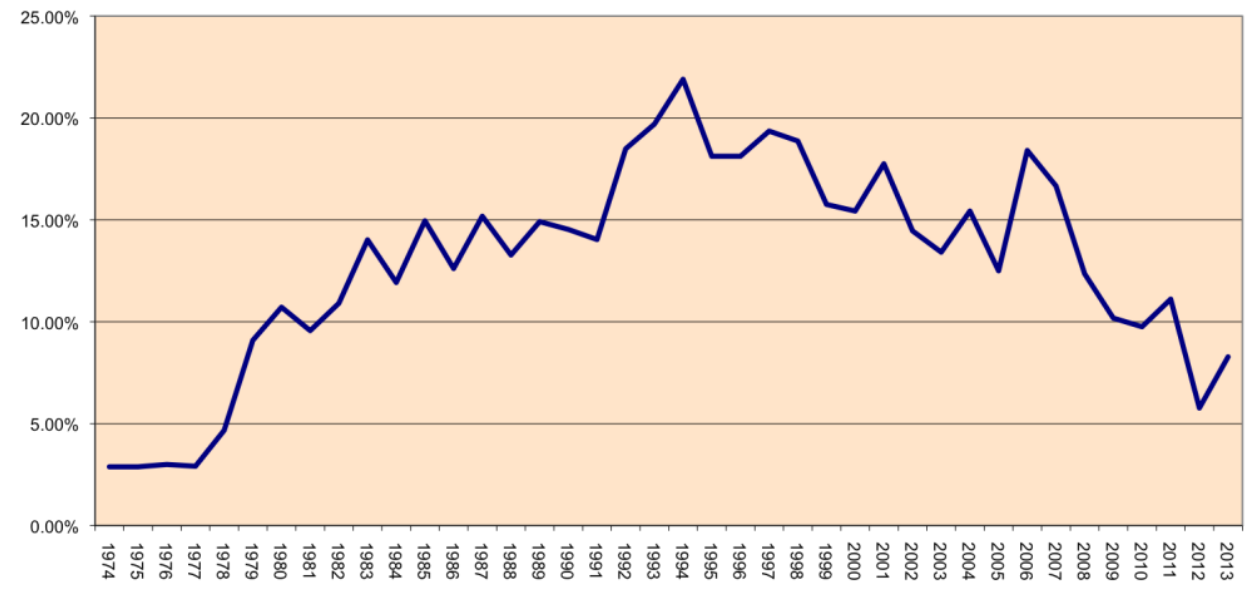

Figure 7. Fear of pegging ( $\%$ of de facto pegs which are not de jure pegs). 


\section{Appendix A. Description of the K-means cluster algorithm ${ }^{22}$}

The following notation is used throughout this appendix unless otherwise stated:

$\begin{array}{ll}N C & \text { Number of clusters requested } \\ \mathbf{M} & i \text { Mean of } i \text { th cluster } \\ \mathbf{X} & k \text { Vector of } k \text { th observation } \\ d\left(\boldsymbol{x}_{i}, \boldsymbol{x}_{j}\right) & \text { Euclidean distance between vectors } \mathbf{x}_{\mathbf{i}} \text { and } \mathbf{x}_{\mathbf{j}} \\ d_{m n} & \min _{\mathrm{i}, \mathrm{j} /} d\left(\mathbf{M}_{i}, \mathbf{M}_{j}\right) \\ \varepsilon & \text { Convergence criteria }\end{array}$

The computation involves three steps.

\section{A.1. Selecting initial cluster centers}

(a) If $\min _{\mathrm{i}} d\left(\boldsymbol{x}_{\boldsymbol{k}}, \mathbf{M}_{i}\right)>d_{m n}$ and $d\left(\boldsymbol{x}_{\boldsymbol{k}}, \mathbf{M}_{m}\right)>d\left(\boldsymbol{x}_{\boldsymbol{k}}, \mathbf{M}_{n}\right)$, then $\boldsymbol{x}_{\boldsymbol{k}}$ replaces $\mathbf{M}_{n}$. If $\min _{i}$ $d\left(\boldsymbol{x}_{k} \mathbf{M}_{i}\right)>d_{m n}$ and $d\left(\boldsymbol{x}_{k}, \mathbf{M}_{m}\right)<d\left(\boldsymbol{x}_{k}, \mathbf{M}_{n}\right)$, then $\boldsymbol{x}_{k}$ replaces $\mathbf{M}_{\mathbf{m}}$; that is, if the distance between $\boldsymbol{x}_{k}$ and its closest cluster mean is greater than the distance between the two closest means $\left(\mathbf{M}_{m}\right.$ and $\left.\mathbf{M}_{n}\right)$, then $\boldsymbol{x}_{k}$ replaces either $\mathbf{M}_{m}$ and $\mathbf{M}_{n}$, whichever is closer to $\boldsymbol{x}_{\boldsymbol{k}}$.

(b) If $\boldsymbol{x}_{\boldsymbol{k}}$ does not replace a cluster mean in (a), a second test is made:

Let $\mathbf{M}_{q}$ be the closest cluster mean to $\boldsymbol{x}_{k}$, and $\mathbf{M}_{p}$ be the second closest cluster mean to $\boldsymbol{x}_{k}$. If $\mathrm{d}\left(\boldsymbol{x}_{k}, \mathbf{M}_{p}\right)>\min _{i} d\left(\mathbf{M}_{q}, \mathbf{M}_{i}\right)$, then $\mathbf{M}_{q}=\boldsymbol{x}_{k}$; that is, if $\boldsymbol{x}_{k}$ is further from the second closest cluster's center than the closest cluster's center is from any other cluster's center, replace the closest cluster's center with $\boldsymbol{x}_{\boldsymbol{k}}$.

At the end of one pass through the data, the initial means of all $N C$ clusters are set.

\section{A.2. Updating initial cluster centers}

Starting with the first case, each case in turn is assigned to the nearest cluster, and that cluster mean is updated. Note that the initial cluster center is included in this mean. The updated cluster means are the classification cluster centers.

\section{A.3. Assign cases to the nearest cluster}

The third pass through the data assigns each case to the nearest cluster, where distance from a cluster is the Euclidean distance between that case and the (updated) classification centers. Final cluster means are then calculated as the average values of clustering variables for cases assigned to each cluster. Final cluster means do not contain classification centers.

When the number of iterations is greater than one, the final cluster means in step 3 are set to the classification cluster means in the end of step 2, and step 3 is repeated again. The algorithm stops when either the maximum number of iterations is reached or the maximum change of cluster centers in two successive iterations is smaller than 8 times the minimum distance among the initial cluster centers.

${ }^{22}$ Based on Hartigan (1975). 


\section{Appendix B. Currencies of reference}

\section{B. 1 To the US dollar}

Afghanistan, Algeria, Angola, Antigua and Barbuda (77-), Argentina, Armenia, Aruba, Australia, Azerbaijan, Bahamas, Bahrain, Bangladesh (79-), Barbados (75-), Belarus (95), Belize (77-), Bolivia, Brazil, Bulgaria (94-95), Burundi (74-83; 93-), Cambodia, Canada, Chile (74-89;99-), China, Colombia, Democratic Republic of Congo, previously Zaire, (74-75;83-), Costa Rica, Curacao \& St. Maarten, Djibouti, Dominica (79-), Dominican Republic, Ecuador, Egypt, El Salvador, Eritrea, Ethiopia, Euro Area, The Gambia (86-), Georgia, Germany (74-98), Ghana, Grenada (77-), Guatemala, Guinea (86), Guyana (76-), Haiti, Honduras, Hong Kong, Hungary (74-93), India (75-), Indonesia, Iran (74-80, 93-), Iraq, Israel, Jamaica, Japan, Jordan (74; 88-), Kenya (74;87-), Korea, Kuwait, Kyrgyz Republic, Lao PDR, Lebanon, Liberia, Libya (74-86), Lithuania (91-01), Macao, Malawi (74; 84-), Malaysia, Maldives, Marshall Islands, Mauritania, Mauritius (83-), Mexico, Micronesia, Mongolia, Mozambique, Nepal (74-84), Netherlands Antilles, New Zealand, Nicaragua, Nigeria, Oman, Pakistan, Palau, Panama, Paraguay, Peru, Poland (74-80), Qatar, Romania (74-03), Russia (74-04), Rwanda (74-82;94-), Sao Tome and Principe, Saudi Arabia, Seychelles (96-), Sierra Leone (83-), Singapore, Solomon Islands (83-), Somalia, South Africa, South Sudan, Sri Lanka, St. Kitts and Nevis (77-), St. Lucia (77-), St. Vincent and the Grenadines (77-), Sudan, Suriname, Syrian Arab Republic, Tajikistan, Tanzania (74; 79-), Thailand, Trinidad and Tobago (76-), Turkey, Turkmenistan, Uganda (74-76; 81-), Ukraine, United Arab Emirates, United Kingdom (74-86; 95-), Uruguay, Venezuela, Vietnam, Yemen, Zambia (74-75; 83-), Zimbabwe.

\section{B.2 To the British pound}

Antigua and Barbuda (74-76), Bangladesh (74-78), Barbados (74), Belize (74-76), Dominica (74-78), The Gambia (74-85), Grenada (74-76), Guyana (74-75), India (74), Ireland (74-78), Seychelles (74-78), Sierra Leone (74-78), St. Kitts and Nevis (74-76), St. Lucia (74-76), St. Vincent and the Grenadines (74-76), Trinidad and Tobago (74-75).

\section{B.3 To the German mark (until 98)}

Albania, Austria, Belgium, Bosnia and Herzegovina, Bulgaria (96-), Croatia, Czech Republic, Denmark, Estonia, Finland, France, Greece, Hungary (94-), Iceland, Ireland (79-), Italy, Macedonia FYR, Moldova, Netherlands, Norway, Poland (80-), Portugal, Slovak Republic, Slovenia, Spain, Sweden Switzerland, United Kingdom (87-94), United States.

\section{B. 4 To the French franc (until 98)}

Benin, Burkina Faso, Cabo Verde, Cameroon, Central African Republic, Chad, Comoros, Republic of Congo, Cote d'Ivoire, Equatorial Guinea, Gabon, Guinea Bissau (7477;84-), Madagascar, Mali, Morocco, Niger, Senegal, Togo, Tunisia, Vanuatu. 
Burundi (84-92), Democratic Republic of Congo, previously Zaire, (76-82), Guinea (7485), Guinea Bissau (78-73) Iran (81-92), Jordan (75-87), Kazakhstan, Kenya (75-86), Latvia (95-04), Libya (87-), Malawi (75-83), Mauritania, Mauritius (74-82), Myanmar, Rwanda (83-93), Seychelles (79-95), Sierra Leone (79-82), Tanzania (75-78), Uganda (77-80), Zambia (76-82).

\section{B.6. To the Euro (from 1999)}

Albania, Austria*, Belgium*, Benin, Bosnia and Herzegovina, Bulgaria*, Burkina Faso, Cabo Verde, Cameroon, Central African Republic, Chad, Comoros, Republic of Congo, Cote d'Ivoire, Croatia, Cyprus*, Czech Republic, Denmark, Equatorial Guinea, Estonia*, Finland*, France*, Gabon, Germany*, Greece*, Guinea Bissau, Hungary, Iceland, Ireland*, Italy*, Latvia (05-), Lithuania (02-), Luxembourg*, Macedonia FYR, Malta*, Madagascar, Mali, Moldova, Montenegro, Morocco, Netherlands*, Niger, Norway, Poland (80-), Portugal*, Senegal, Slovak Republic*, Romania (04-), Serbia (02-), Slovenia*, Spain*, Sweden, Switzerland, Togo, Tunisia, United States.

\section{B.7. Other}

Bhutan, Indian Rupee.

Brunei Darussalam, Singapore Dollar.

Botswana, South African Rand.

Chile (90-98), Central band parity as published by the Central Bank of Chile.

Cyprus, ECU (90-98).

Fiji, Australian Dollar.

Kiribati, Australian Dollar.

Lesotho, South African Rand.

Luxembourg (74-98), Belgium Franc.

Malta (74-98), Italian Lira.

Namibia, South African Rand.

Nepal, Indian Rupee (85-).

Papua New Guinea, Australian Dollar.

Russia (05-), Dual Currency Basket (Dollar-Euro).

San Marino, Italian Lira/Euro.

Solomon Islands (74-82), Australian Dollar.

Swaziland, South African Rand.

Tonga, Australian Dollar.

*Members of the Eurozone:

Joined in 1999: Austria, Belgium, Finland, France, Germany, Ireland, Italy, Luxembourg, Netherlands, Portugal, Spain. 
Joined in 2001: Greece.

Joined in 2007: Slovenia.

Joined in 2008: Cyprus, Malta.

Joined in 2009: Slovak Republic.

Joined in 2011: Estonia.

\section{Appendix C}

The regimes for all countries are given in Table 5 . 
Appendix C. Regimes

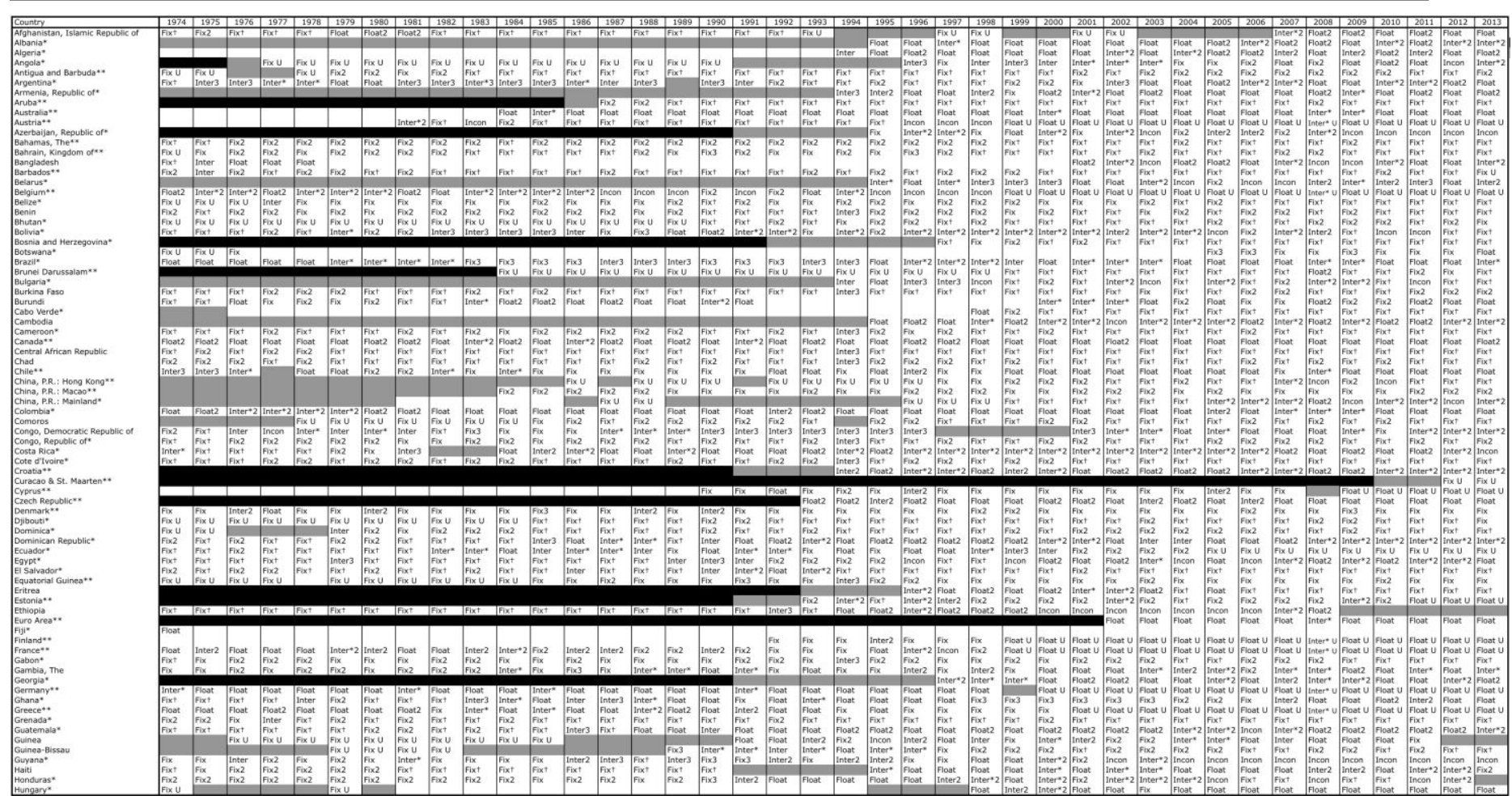


Appendix 5 (Continued)

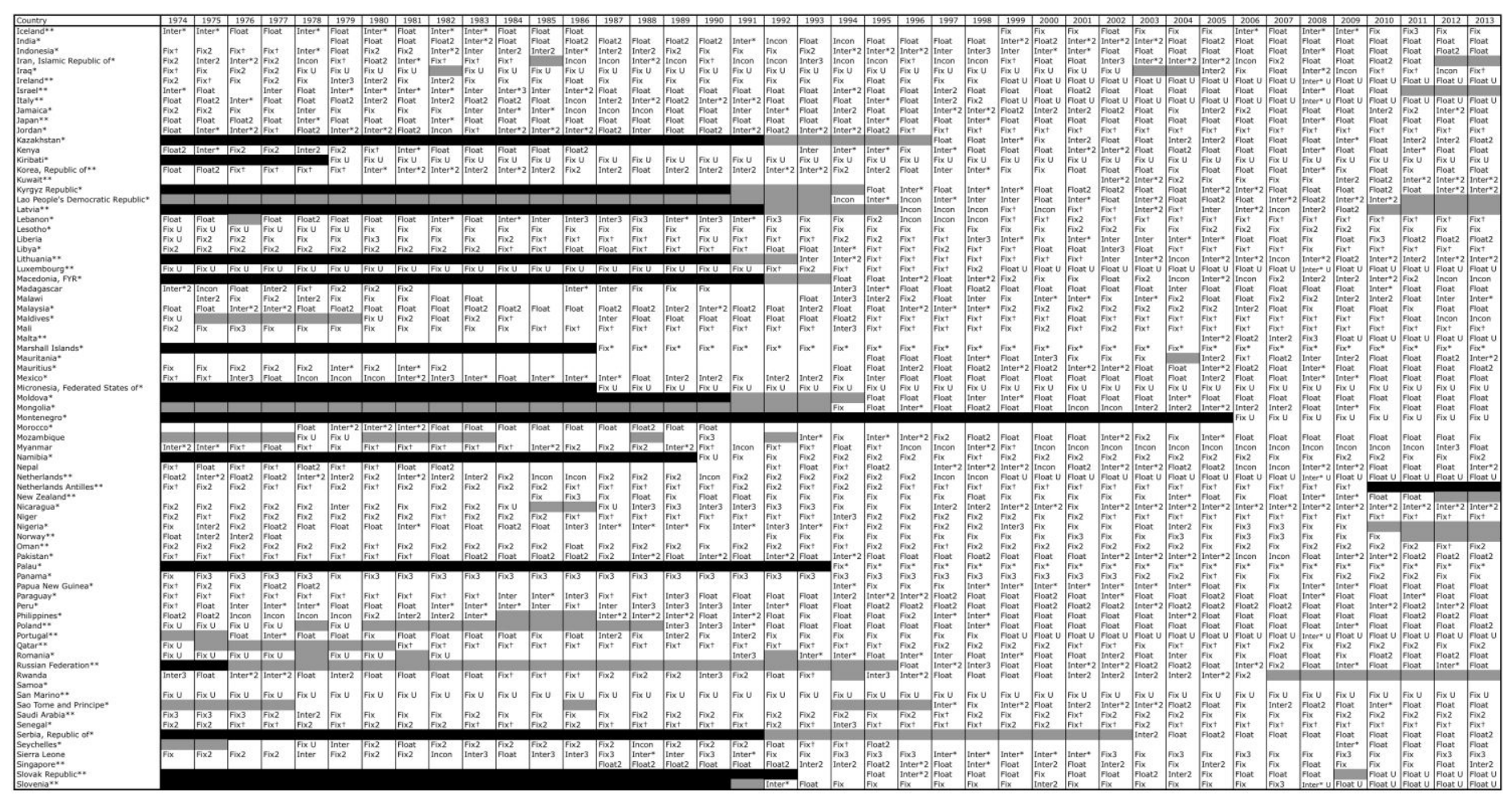




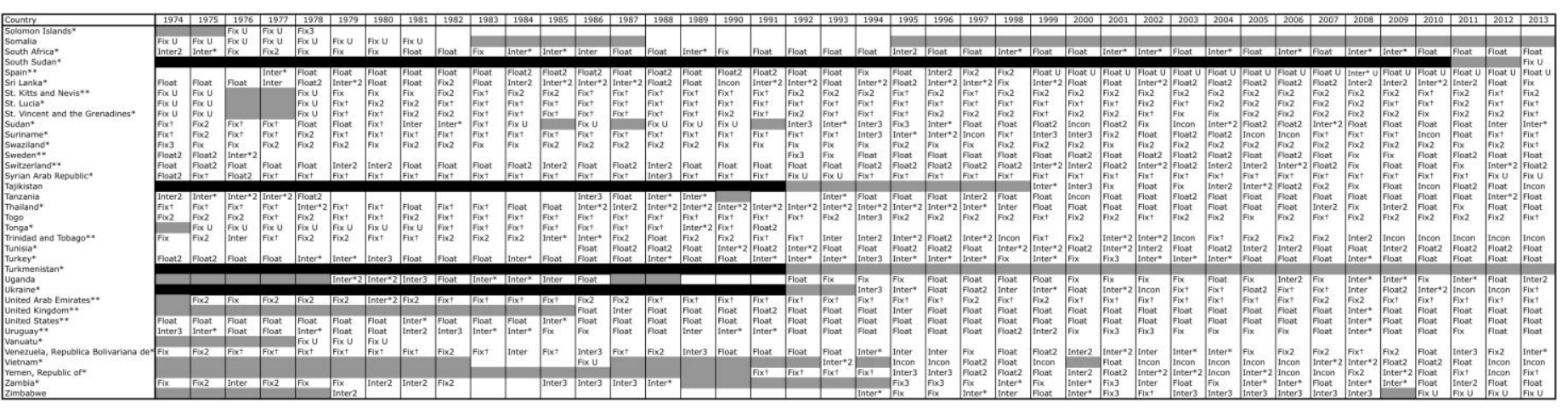

Basket.

Not existing or not independent country.

$\begin{array}{ll} & \text { One classification } \\ & \text { Fixt Inconclusives }\end{array}$

$\begin{array}{ll}\text { Fixt } & \text { Fixt Inconclusive } \\ \text { Incon } & \text { Inconclusives }\end{array}$

Inter Dirty.

$\begin{array}{ll}\text { Inter* } & \text { Dirty/CP } \\ u & \text { Uncontroversials }\end{array}$

$2 \quad$ Classified in second round

Outliers 